\title{
Team Adaptation in the Operation of Mega Morbid Patient
}

\author{
Kucur E, Tulubas, Seyit H, Derya K Peker, Kosuk H, Hergunsel 0, Alis H and Demir G* \\ Bakrkoy Dr. Sadi Konuk Research and Training Hospital, Turkey
}

Submission: February 08, 2017; Published: August 11, 2017

*Corresponding author: Guray Demir M.D, Associate Professor, Bakirkoy Dr. Sadi Konuk Research and Training Hospital, Anesthesiolgy and Critical Care Medicine, Istanbul, Turkey, Email: guraydemir@hotmail.com

\section{Introduction}

Obesity is a preventible health problem which is becoming increasingly common in the world and becoming one of the important health problems. Obesity affects the quality and duration of life significantly [1]. It is increasing rapidly especially in young people and many chronic illnesses are developing at earlier ages. The socioeconomic burden is also increasing associated with it.Sustainable diet has a very important role in the treatment of obesity, but it seems nearly impossible to do it with severe obesity. At this point, surgical treatment is an appropriate and effective option for morbid obesity. Obese patients are a patient group which are difficult to manage due to anesthesia because of the lack of consensus on increased co-morbidity, difficult intubation and drug distribution. People with body mass index (BMI) $>40 \mathrm{~kg} /$ $\mathrm{m} 2$ are defined as morbid obesity and BMI $>60$ are defined as super obese [2]. In this article, we aimed to present the anesthesia management of a super obese patient (240kg BKI:106kg/m2) in laparoscopic sleeve gastrectomy (LSG.). This case, as we know, is the patient with highest VKI had LSG surgery in our country.

\section{Case}

Obese patients are being consulted with chest diseases, cardiology, endocrine and psychiatry by protocol of our hospital. Preoperative laboratory values after routine consultations were normal in this case. LSG was planned to a 36-year-old patient with a $150 \mathrm{~cm}$ lenght, $240 \mathrm{~kg}$ weight and a BMI of $106 \mathrm{~kg} /$ $\mathrm{m} 2$. The ideal weight was calculated as $45 \mathrm{~kg}$ (ideal weight in women=height-105). Comorbidities were: sleep apnea syndrome requiring remitting CPAP (continuous positive airway pressure), DM and HT. The history of previous surgery and allergy was not available in that case.

It was reported in the consultation of chest diseases that bilateral respiratory sounds were deeply and no lesion was found in parenchyma on PA lung graphy. FEV1:61, FEV1/FVC:121 were reported in the pulmonary function test. Preoperative blood gas samples, with spontaneous respiration, were reported as
pH:7.32,PO2:64, PCO2: 52, HCO3: 26. There was sinus rhythm seen in the ECG and for the ecocardiography, EF was reported as 55\% at the cardiology consultation. Any additional cardiac pathology wasn't exist. There was not found any pathology could cause disability for surgery at endocrine and psychiatric consultation.

In airway evaluation, mallopathy classification was determined as class 2 . Thrombus was not detected in the lower extremity venous colour doppler USG. Our patient could walk at close range without assistance. Our patient was brought to the operating table as the head would be 30 degrees from inpatient service. She was admitted to the ramp position during the operation. No premedication was performed. Pulse oximetry, three-way ECG monitoring and BIS (bispecific index) monitoring were performed when the patient arrived at the table. The invasive arterial monitorization was performed from the left radial artery following the allenal test because the patient's arm wasn't appropriate for blood pressure cuff and sudden hypotension could happen after induction. The blood gas sample, taken before the induction, values were SPO2: 88, PCO2: 52, pH: 7.32, HCO3: 25. A video laryngoscope was used for intubation. Besides, macintosh laryngoscope, emergency tracheostomy set and stile prepared too.

The patient received $3 \mathrm{mg}$ midazolam, $1 \mathrm{~g}$ paracetamol and $100 \mathrm{mg}$ tradamol before induction. Vigilant intubation was not preferred due to the concern that uncontrolled movements of people with this weight may pose a risk for patient safety. Antidote medicines, which will quickly reverse the effects of the drugs used during induction, were available at the desk. Flumazenil were available for dormicum and sugammadex were available for rocuronium. $250 \mathrm{mg}$ of propofol and $100 \mathrm{mg}$ of rocuronium were administered to ensure adequate anesthesia depth in all 3 minutes by following the BIS (bispecific index). Intubation were performed in one shot by using the videolaryngoscope. Intubation was confirmed by Et $\mathrm{CO} 2$ because obesity-related lung sounds were not fully audible. After the intubation, $150 \mathrm{mcg}$ of fentanyl, 
$100 \mathrm{mg}$ of tramadol, $50 \mathrm{mg}$ of ranitidine, and $8 \mathrm{mg}$ of ondansetron were administered.

Sevofluran was initiated with 0,9 MAC (minimum alveolar concentration) and remifentanyl was initiated ata dose of $0.05 \mathrm{mcg} /$ $\mathrm{kg} / \mathrm{min}$, and also titrated during the anesthesia procedure due to the blood pressure and heart rate. At the 45th minute of operation $20 \mathrm{mg}$ rocuronium was added. Patient was ventilated with PRVC (Pressure Regulated Volume Control) mode to permit up to 50 $+/-50 \%$ of et $\mathrm{CO} 2$ peroperatively, due to the fact that there were $50 \mathrm{mmHg}$ of $\mathrm{PCO} 2$ in the blood gas taken before the intubation. Monitor settings were made as PEEP (positive end-expiratory pressure): $7 \mathrm{~cm} / \mathrm{H} 2 \mathrm{O}$, TV (tidal volume): $480 \mathrm{ml}$, Fr (frequency): 14 per minute, FiO2: $60 \%$. The blood gases taken before the start of surgery were reported as pH:7.36, PCO2:52mmHg, PO2: $137 \mathrm{mmHg}$ and pH:7.31, PCO2:54 mmHg, P02:110mmHg were after surgery. The intra-abdominal pressure was set at $18 \mathrm{mmHg}$ to provide adequate surgical vision.

During the operation, a total of $800 \mathrm{cc}$ (for ideal weight: $10 \mathrm{ml} /$ min) of fluid was given and a total of $100 \mathrm{cc}$ urination (for ideal weight: $1.1 \mathrm{ml} / \mathrm{h}$ ) was withdrawn. The duration of the operation was $90 \mathrm{~min}$ and the duration of the anesthesia was $120 \mathrm{~min}$. Decurarisation was provided with $400 \mathrm{mg}$ of sugammadex and patient was extubated after her spontaneous breathing was adequate. The patient was transferred to PACU (Post-op Anesthesia Care Unit), connected to its own CPAP device. After extubation, $\mathrm{pH}$ was found to be 7.45 , PCO2:55mmHg, PO2:70mmHg in the blood gas. The patient underwent an intermittent CPAP mask for one day stay in PACU. Blood glucose levels ranged from 100 to 110 in PACU. The hourly urine output was found to be $1.2 \mathrm{ml} / \mathrm{h}$ on an ideal weight basis. The day after the PACU she was sent to the service and mobilized. On the sixth postoperative day, the patient was discharged without any complications.

\section{Discussion}

There are several problems for anesthesia management in a super-obese patient. These are especially airway management, anesthetic drug selection and dosage, fluid management and administration of postoperative analgesia.

While planning the anesthesia management of this case, with a 700 obesity cases of experience, we planned as follows:

1) Completion of preopretive consultations

2) Presence of three anesthetists for anesthesia

3) Patient with a ramp position during induction and application of anesthetic agents according to ideal weight and their titration according to BIS monitoring, blood pressure and heart rate

4) Complete preparation for difficult intubation

5) Hemodynamic monitoring was performed with intraarterial cannulation because of the absence of an appropriate blood pressure cuff fort his patient and for follow up

6) PRVC mode ventilation

7) Postoperative pain control was achieved with PCA.

The ramp position in morbid obesity during induction improves laryngoscopy vision and facilitates intubation. In addition, the oxygenation is better because the pressure of the abdominal organs to diaphragma decreases in this position, so the apnea period is tolerated better. During anesthesia induction, midazolam, propofol and rocuronium were used. After intubation $150 \mathrm{mcg}$ of fentanyl was added. Intravenous paracetamol and tramadol were administered. There are debates about medicines used in superobese patients whether would be based on deal body weight or not. The ideal weight of the patient is $55 \mathrm{~kg}$ and the corrected weight is $64 \mathrm{~kg}$. Because of propofol and remifentanyl are high lipophilic drugs, they can accumulate beyond estimates in fatty tissue. However, remifentanil is rapidly metabolized and is not expected to accumulate in fatty tissue. Therefore, remifentanyl is adjusted by titration to ideal weight.

Patient-controlled propofol was successfully applied to a $290 \mathrm{~kg}$ patient over the ideal weight according to servin et al. [3]. However, Arveles et al. [4] used propofol induction over the ideal weight over microgram $/ \mathrm{kg}$. Midazolam is calculated according to ideal weight also. Because sevoflurane is also a lipophilic drug, it can cause overdose over the expected dose. For this reason, there is no consensus in the literature about its use in obese patients. However, it has been successfully used in this case based on our clinical experience. $0.4 \mathrm{mg} / \mathrm{kg}$ of rocuronium was used according to actual body weight. Because of rocuronium is a hydrophilic drug, it does not differ much between obese patients and other patient groups. It is recommended that rocuronium induction is used due to ideal weight, but it has not been sufficient to provide relaxation in this condition. Compared to the ideal weight of rocuronium, the duration of effection of it is more than twice times that of patients actual weight.

In this case, the use of rocuronium according to the actual weight shortened the duration of intubation and at the same time the antidote prevented postoperative residual drug remained. Because of the patient's sleep apnea, $45 \mathrm{~cm}$ of neck circumference and her small mouth we had preparation for difficult intubation. Gaszynski et al. [5] emphasized that the videolaryngoscope provides better laryngeal images and that makes intubation to be faster. We chose to use a videolaryngoscope because we had a lot of clinical experience in this type of difficult intubation. At one time, the patient was intubated successfully with the videolaryngoscope. Except the high BMI, $45 \mathrm{~cm}$ of the neck circumference increased the risk of the difficult intubation. PVRC mode was used for ventilation. Hans and colleagues [6] reported that they obtained high tidal volume with low pressure throughout the operation, although they did not find any difference between volumetric control and PVRC on partial oxygen and carbon dioxide levels. 
PEEP is set to $7 \mathrm{~cm} / \mathrm{H} 2 \mathrm{O}$. Tradamol and paracetamol were preferred for postoperative analgesia. The epidural catheter was not preferred because of its technical difficulties in this patient group. Low-molecular-weight heparin $60 \mathrm{mg}$ enoxaparin sodium) was started 12 hours before the operation to reduce thromboembolic risk. During the operation the patient was wearing anti-embolic socks. After extubation, she was taken to PACU and intermittent CPAP was applied. Early post-operative mobilization was emphasized and LMWH continued during this period. On the first postoperative day, the vital signs were stabilized and oxygenation in the blood gas sample was as same as the preoperative values. In the service follow up, postop 1stDay only water was given and on the 2 nd day clear liquid nutrition was given to the patient. The patient, whose respiratory exercise and mobilization was increased, discharged on postoperative 4th day.

\section{Result}

It is obvious that super-obese patients have many difficulties for anesthesia management. However, with appropriate preventions and the presence of experienced team partly facilitates that management. We performed a super obese case of LSG in this operation; We believe that while performing LSG in that case medications according to the ideal body weight, PVRC mode ventilation and the pain control with tradomal and paracetamol made this case successful.

\section{References}

1. Field AE, Coakley EH, Must A, Jennifer LS, Nan Laird, et al. ( 2001) Impact of Overweight on the Risk of Developing Common Chronic Diseases During a 10-Year Period. Arch İntern Med 161(13): 15811586.

2. (1995) Weighing the Options. In: Paul R Thomas (Ed.), Guidance for Treat. Institute of Medicine National Academy Press Washington DC, USA.

3. Servin F, Farinotti R, Haberer JP, Desmonts JM (1993) Propofol infusion for maintenance of anesthesia in morbidly obese patients receiving nitrous oxide. A clinical and pharmacokinetic study. Anesthesiology 78(4): 657-665.

4. Alvarez AO, Cascardo A, Menendez SA, Capria JJ, Cordero RA (2000) Total intravenous anesthesia with midazolam, remifentanil, propofol and cisatracurium in morbid obesity. Obes Surg 10(4): 353-360.

5. Gaszynski T, Pietrzyk M, Szewczyk T, Gaszynska (2014) A comparison of performance of endotracheal intubation using the Levitan FPS optical stylet or Lary-Flex videolaryngoscope in morbidly obese patients. The Scientific World Journal. P. 9.

6. Hans GA, Pregaldien AA, Kaba A, Sottiaux TM, de Roover A, et al. (2008) Pressure-controlled ventilation does not improve gas exchange in morbidly obese patients undergoing abdominal surgery. Obes Surg 18(1): 71-76.

\section{Your next submission with Juniper Publishers will reach you the below assets}

- Quality Editorial service

- Swift Peer Review

- Reprints availability

- E-prints Service

- Manuscript Podcast for convenient understanding

- Global attainment for your research

- Manuscript accessibility in different formats

( Pdf, E-pub, Full Text, Audio)

- Unceasing customer service

Track the below URL for one-step submission https://juniperpublishers.com/online-submission.php 